\title{
Thoughts on Movement, Growth and an Anthropologically-Sensitive IS/Organization Studies: An Imagined Correspondence with Tim Ingold
}

\author{
Tim Ingold ${ }^{1}$, Lucas Introna ${ }^{2}$, Donncha Kavanagh ${ }^{3}$, Séamas Kelly ${ }^{4}$, Wanda Orlikowski ${ }^{5}$, and Susan Scott ${ }^{6}$ \\ ${ }^{1}$ University of Aberdeen, Department of Anthropology, Aberdeen AB24 3QY, Scotland, UK \\ tim.ingold@abdn.ac.uk \\ ${ }^{2}$ Lancaster University, Lancaster University Management School, Lancaster LA1 4YX, UK \\ L.Introna@lancaster.ac.uk \\ ${ }^{3}$ University College Dublin, UCD College of Business, Belfield, Dublin 4, Ireland \\ donncha. kavanagh@ucd. ie \\ ${ }^{4}$ University College Dublin, UCD College of Business, Belfield, Dublin 4, Ireland \\ seamas.kelly@ucd.ie \\ ${ }^{5}$ MIT Sloan School of Management, 100 Main Street (E62-418), Cambridge, MA 02142, USA \\ wanda@mit.edu \\ ${ }^{6}$ London School of Economics and Political Science, Department of Management, Houghton St, London WC2A 2AE, UK \\ $\underline{\text { s.v.scott@lse.ac.uk }}$
}

In what follows, we present the outcome of an imagined dialogue with Tim Ingold on possible future directions for an anthropologically-sensitive approach to studying Information Systems (IS) and Organization Studies (OS). The aim is to try to convey some of the strangeness and freshness that we have found in his thought, with a view to stimulating IS/OS scholars to engage further with his work and ideas. The piece takes the form of an imagined Q\&A session with Tim, which we have synthesized from excerpts of previously published interviews and writings.

\section{Q: Liveliness, movement and engagement are central themes in your ecological} approach to anthropology. Can you tell us a little about where these themes came from?

I am the son of a prominent mycologist and grew up with that sense of science as something you do in a very homely way, involving observation and drawing. And I think that is somehow very deeply embedded in the way I think.

My father's scientific practice involved walks along river banks where he would collect the scum that often accumulates in brackish pools, bringing it home in glass phials to be investigated under a microscope set up on our dining room table. He had improvised an elaborate contraption involving a pile of volumes of the Encyclopaedia Britannica, a glass plate and an early version of the anglepoise lamp, which allowed him to project the forms of the fungi revealed under the microscope so that they could be accurately drawn. This he did with the utmost care, using a mapping pen, Indian ink and high quality Bristol board.

Though he would never admit to it, this was his way of honouring the forms of nature, of not just contemplating their beauty but knowing them from the inside; and the results were true works of art. He loved his fungi. But perhaps what I did not realize at the time was that as a field of the botanical sciences, mycology is a deeply subversive discipline. Fungi, you see, just don't behave as organisms should. We typically describe the organism as a blob-like entity with an inside and an outside, bounded by the skin, and interacting with the surrounding environment across the boundary. But fungi are not like that. They leak, they ooze, their boundaries are indefinable; they fill the air with their spores and infiltrate the ground with their meandering, ever-branching and ever-extending fibres. What we see above ground are merely fruiting bodies, like street-lamps which cast their aerial illumination only thanks to hidden, subterranean circuitry.

\section{Q: How did this early exposure to the practices of science of your father shape your engagement with it?}


At school, guided by inspirational teachers, I sat at the edge of my seat in wonder at the mysteries of the universe as they were being unravelled by science. I experimented with cloud chambers and grew crystals in solution. It was obvious that I was going to be a mathematician and a scientist. A year of studying natural sciences at the University of Cambridge, however, put paid my illusions. After the excitement of school science, lectures at Cambridge were an intense disappointment. I found much of what was taught intellectually claustrophobic, dedicated to the regimented and narrow-minded pursuit of objectives that seemed remote from experience. Unlike many of my fellow students, outraged by science's renunciation of its democratic principles and its surrender to the mega-machines of industrial and military power - this was, after all, a time when the war in Vietnam was at its height - I never became radically hostile to the scientific project. But I could see no future in it for myself. I wanted to study something in which there was room to grow, where I could discover the world and myself at the same time. And that was what led to anthropology. There is an enormous division in the university between the natural sciences, on the one hand, and the arts and humanities, on the other. I was looking for a subject to study that would help to bridge and transcend that division.

It seems to me that, over the course of my lifetime, science has increasingly lost its ecological bearings, while the arts have increasingly gained them. As regards the journey in my own teaching and research, I now imagine it as an Odyssey - a journey home - to the kind of science imbibed in childhood, as the son of a mycologist. This was a science grounded in tacit wonder at the exquisite beauty of the natural world, and in silent gratitude for what we owe to this world for our existence. Today's science, however, has turned wonder and gratitude into commodities. They no longer guide its practices, but are rather invoked to advertise its results. The goals of science are modelling, prediction and control. Perhaps this is why, more and more, we turn to art to rediscover the humility that science has lost? It seems to me that the people who are doing what I understood forty years ago - to be science are now artists. Thus, my project is now one that seeks to integrate anthropology with the practices of art, architecture and design.

\section{Q: What, then, made you an anthropologist?}

It is commonly supposed that anthropology is a centrifugal discipline that discharges its practitioners into fields as remote and far away as possible, in order that they may experience ways of life as different from their own as they could hope or expect to find. Many anthropologists would agree, flaunting their encounter with "radical alterity" as a badge of honour. But for me, it has always felt the other way around. Ever since I embarked on my studies of the subject, anthropology has been about finding my way home. I had no settled point of origin from which to start. It was not as though, even before setting out, I already knew all there was to know about myself and what I was going to be. Like most apprentice anthropologists, I did go to a relatively distant place to undertake fieldwork, and in my case this involved a prolonged stay among Skolt Saami people in the far northeast of Finland.

At the time, however, I had almost no idea of whom I was or where I came from, let alone of where I was going. I had a name and address, a passport, and next of kin to be contacted in case of emergency; I even had a degree from a respected university and a scholarship to support my work. But the voice with which I spoke, the hand with which I wrote, even the mind with which I thought - these were not yet me. They were but habits I had borrowed or styles that I had, at one time or another, sought or been trained to emulate. In that sojourn in Lapland, however, and through the moral education it gave me, I took my first, tentative steps homeward. The road has been long and tortuous. I have not arrived yet, and probably never will. But I am now more confident that it is indeed my voice that speaks, my hand that writes and my mind that thinks. With voice, hand and mind I now declare: This is who I am.

\section{Q: How would you like to see your kind of anthropology develop?}

The way I see anthropology is that it lies at the crossroads of two divisions: one between the humanities and the natural sciences; the other between theoretical speculations about what human life could be like and empirical observation of what human life is like, somewhere, sometime. I would like to bring anthropology back to the centre, where I think it belongs, in public debates about what it means to be human, about freedom, about responsibility, about ethics. At the moment it isn't there. Instead, the ground is being occupied by psychologists, historians and economists, and what they say often perpetuates - rather than dispels - prejudice and misunderstanding. I worry that anthropology has allowed itself to fall below the horizon of public 
consciousness. We need much more ambition in what we do. But, in a way, the debates don't change. The fundamental questions are still: what does it actually mean to be a human being in the world; what is language all about; how is it that we perceive the way we do; how can we remember things; why do we tell stories all the time? These are basic anthropological questions.

\section{Q: What might this mean for the practice of anthropology? Or, more specifically, what might be entailed by an ecological anthropology?}

The mycologist Alan Rayner once remarked to me, in passing, that the whole of biology would be different had the fungal mycelium - rather than, say, a mouse or a sea-urchin - been taken as a prototypical exemplar of the organism. Many years later, this thought would come back to haunt me - what if we were to think of the person, like the fungal mycelium, not as a blob but as a bundle of lines, or relations, along which life is lived? What if our ecology was of lines rather than of blobs? What then can we mean by "environment"? People, after all, don't live inside their bodies, as social theorists sometimes like to claim in their clichéd appeals to the notion of embodiment. Their trails are laid out in the ground, in footprints, paths and tracks, and their breaths mingle in the air. They stay alive only as long as there is a continual interchange of materials across ever-growing and ever-shedding layers of skin. Thus, just as mycology subverts deeply held intuitions in the biological sciences, so - it now seems to me - anthropology does the same for the social sciences. Anthropologists, mycologists of the social, are the awkward squad, the jesters, the fools, who sidle up to power and chip away at its pretensions. And perhaps their awkwardness lies in precisely this: that they see a world of intricately enmeshed relations rather than one already divided into discrete and autonomous entities.

In the latter years of his life, my father used to rail against the way, in his view, biological science had lost touch with the reality of living organisms. He found much of the literature incomprehensible. It was produced by modellers who had never observed or handled anything that lived or grew upon this earth, and who spent their time in laboratories or in front of computers, analysing massive datasets spewed out by machines from the stuff fed into them. In the spectacular and lavishly funded rise of e-social science we have seen much of the same. Fuelled by the digital revolution, it has become an immense data-processing exercise from which the people have effectively disappeared. In the social as in the biosciences, qualitative field-based inquiries with living people or living organisms are increasingly regarded as naïve or amateurish. It is as though science had turned its back on the living, avoiding sentient involvement of any kind. In this brave new world, life is disposable, and its forms - whether human or non-human - are mere grist to the mill of data-analytics, the purpose of which is to produce results or "outputs" whose value is to be judged by measures of impact or utility rather than by any appeal to truth.

A datum is, by definition, that which is given. But what today's scientists count as data have not been bestowed as any kind of gift or offering. To collect data, in science, is not to receive what is given but to extract what is not. Whether mined, washed up, deposited or precipitated, what is extracted comes in bits, already broken off from the currents of life, from their ebbs and flows, and from their mutual entailments. For the scientist even to admit to a relationship of give and take with the things in the world with which he deals would be enough to disqualify the inquiry and any insights arising from it. Ideally he should leave it all to his recording equipment and exit the scene, only to return to register the outcomes once the job is done and to transfer them to a databank or storage facility for safe keeping. That this is impossible in practice - especially in the field sciences for which the laboratory is nothing less than the world we live in, and from which there is no escape is often considered a shortcoming, a weak point in the methodological armoury that could compromise the objectivity of the results. For what is methodology, if not a shield to protect the researcher from direct sensory contact with materials? The prescriptions of methodology treat the researcher's own presence not as an essential prerequisite for learning from what the world has to offer us, but as a source of observer bias to be reduced at all cost. Any science that fails in this regard is considered to be methodologically "soft", and anthropology by that measure - and mycology too, as my father used to practise it - is positively squishy.

\section{Q: So this "squishiness" needs to be celebrated and embraced by anthropologists?}

Yes indeed! Let us compare a hard object - say a ball - with a squishy one. The first, when it comes up against other things in the world, can have an impact. It can hit them, or even break them. In the hard sciences, every hit 
is a datum; if you accumulate enough data, you may achieve a breakthrough. The surface of the world has yielded under the impact of your incessant blows, and having done so, yields up some of its secrets.

The squishy ball, by contrast, bends and deforms when it encounters other things, taking into itself some of their characteristics while they, in turn, bend to its pressure in accordance with their own inclinations and dispositions. The ball responds to things as they respond to it. Or in a word, it enters with things into a relation of correspondence. In their practices of participant observation - of joining with the people among whom they work and learning from them - anthropologists become correspondents. They take into themselves something of their hosts' ways of moving, feeling and thinking, their practical skills and modes of attention. So too, my father corresponded with the fungi as he drew their forms under the microscope. His hand, along with the pen it held, was drawn into their formative processes, and as he drew the forms re-emerged on the surface of the board. Correspondence, whether with people or with other things, is a labour of love, of giving back what we owe to the human and non-human beings with which and with whom we share our world, for our own existence and formation.

Two centuries ago, in Germany, Johan Wolfgang von Goethe proposed a method of science which demanded of practitioners that they should spend time with the objects of their attention, observe closely and with all their senses, draw what they observed, and endeavour to reach a level of mutual involvement or coupling, in perception and action, such that observer and observed become all but indistinguishable. It is from this crucible of mutual involvement, Goethe argued, that all knowledge grows.

\section{Q: What became of Goethe's vision - this notion of a sensual and involved science?}

I have a strong suspicion that the virulent repudiation of what we could call the science of correspondence coincides in a way that is not accidental with the colossal expansion, over the last four decades, of globalization and the political economy of neoliberalism. These, of course, were the decades of my career as a professional anthropologist. What I have witnessed, over these decades, is the surrender of science to the forces of neoliberalism. And to find a counter-movement in the contemporary world, we have to turn not to science but to art.

\section{Q: So anthropology might be understood as a form of art?}

What might pejoratively be regarded as squishy science could, I think, be better and more positively described as the art of inquiry. In this art, every work is an experiment: not in the natural scientific sense of testing a preconceived hypothesis or of engineering a confrontation between ideas "in the head" and facts "on the ground", but in the sense of prising an opening and following where it leads. You try things out and see what happens. Thus the art of inquiry moves forward in real time along with the lives of those who are touched by it, and with the world to which both it and they belong. Far from matching up to their plans and predictions, it joins with them in their hopes and dreams. This is the very opposite of methodology.

It is not to wrap method up into an impregnable shell, protecting the investigator from having to share in the suffering of those subjected to his hard-ball tactics, but rather to compare method to a way of working, akin to a craft, which opens up the world to our perception, to what is going on there, so that we in turn can answer to it. We could call it the method of hope: the hope that by paying attention to the beings and things with which we deal, they in turn will attend to us, and respond to our overtures. Anthropology, I believe, can be an art of inquiry in this sense. We need it not to accumulate more and more data about the world, but to better correspond with it.

\section{Q: How does this view square with traditional conceptions of the anthropological project?}

This is not the way in which most practising anthropologists currently think about their discipline. The majority of my colleagues would insist that the primary task of the anthropologist is ethnographic: that is, to give a richly detailed, accurate and nuanced account of life as it is lived for particular peoples in particular times and places. There is absolutely nothing wrong with this, of course, just as there is nothing wrong with a history of art that looks back on how artworks have been made and received, again in specific times and places. For ethnography as for the history of art, understanding is about putting things in context. Yet for all its manifest scholarly virtues, to put things in context is also to lay them to rest, to silence them or neutralize their power, so that the 
things themselves cease to engage our attention as active and ongoing forces in the world. They are, so to speak, accounted for, ticked off, put in their place. But people don't act, nor do artists work, in order that their deeds and works may be accounted for by future historians. They act and work in order to make a difference in the world. Thus to create a work of art is to give birth to a new being, a being that will have its own life, alongside the lives of those who touch and are touched by it. The thing springs up, and like a rebellious child, refuses the efforts of its elders to put it to bed.

Anthropology, for me, is not about describing the world, or wrapping it up. It is, in the first place, about attending to presence, about noticing, and responding in kind. It means acknowledging that persons and other things are there, that they have their own being and their own lives to lead, and that it behoves us, for our own good, to pay attention to their existence and to what they are telling us. Only then can we learn. The same, I think, might be said for art. It too is an opening on the world rather than an attempt at closure - an opening that exposes the practitioner to its trials and to its gifts. That is why art combines well with anthropology but not with ethnography. For what art and anthropology open up, ethnography - like art history - seeks to contain.

\section{Q: Is this notion of anthropology as art likely to be dismissed as "unscientific" within the contemporary academic world?}

Very probably. I remember the science of my childhood, grounded in tacit wonder at the exquisite beauty of the natural world, in care, attentiveness and in silent gratitude for what we owe the world for our existence. Much of today's science, however, has turned wonder and gratitude into commodities. They no longer guide its practices but are rather invoked to advertise its results. Science has even enlisted art to promote its hard-sell, to offer images that beautify its results, soften its impact and mask its collusion with corporations whose only interest in research is that it should "drive innovation". For in the neoliberal economy of knowledge, only what is new sells. True, much scientific research, in what is nowadays known as "academia", lacks immediate application. It is said to be curiosity-driven or "blue sky". Scientists have been vociferous in defending their right to undertake blue-sky research. But in the land of academia, curiosity has been divorced from care, freedom from responsibility. Academia's income comes from its exports of knowledge, but it is left to those who buy the knowledge to determine how it should be applied, whether to build bombs, cure disease or rig markets. Why should scientists care? This attitude reveals the lofty appeal to blue skies to be little more than a self-serving defence of special interests increasingly concentrated in the hands of a global scientific elite which, in collusion with the corporations it serves, treats the rest of the world - including the vast majority of its increasingly impoverished and apparently disposable human population - as a standing reserve of data to feed the insatiable appetite of the knowledge economy.

We should care, of course, because truth matters. And the responsible search for truth demands that care and curiosity go together. They are really two sides of the same coin. We are curious about the well-being of people we know and love, and never miss an opportunity to ask them how they are doing. That is because we care about them. Should it not be the same for the world around us? Is not curiosity a way of caring? Not, it must be said, according to the protocols of normal science which require, in the name of objectivity, that we sever all personal relations with the things we study, and remain unmoved and unperturbed by their condition. We owe them nothing, according to these protocols, and they offer us nothing in return.

It is a great mistake, however, to equate the pursuit of objectivity with the pursuit of truth. For if the former prescribes that we cut all ties with the world, the latter demands our full and unqualified participation. I may be being childish or naïve, but in my innocence I still believe in science as the pursuit not of innovation but of truth. And by truth I do not mean fact rather than fantasy, but the unison of experience and imagination in a world to which we are alive and that is alive to us. It is a truth that comes not after science, in its proud record of discoveries and achievements, but before science, in the more humble recognition that we are ourselves beholden, for our very existence, to the world we seek to know. Thus the movement from science to art, in my thinking and in my teaching, did not take me further away from science but further into it, into the very conditions of its possibility. I have gone from science to art and back again. 


\section{Q: We typically conceive of the social and natural worlds as separate, but you have been very keen to get beyond any such dichotomy. What would it mean to think beyond our conventional distinctions between cultural and natural phenomena?}

Sociocultural anthropology established itself as an independent sub-discipline by designating the social and cultural as a specific domain of study, allowing it to distance itself from certain retrograde positions found within the domain of physical anthropology. However, the nature/culture dichotomy on which this division was based has been the object of sustained criticism. The challenge for our discipline is to define an anthropology beyond nature and culture.

\section{Q: But what does this imply for the way we think about being human in the world?}

I contend that person and organism are one and the same; the organism-in-its-environment is a being-in-theworld. To follow this through requires a completely different kind of thinking, one that starts not from populations of individuals but from fields of relations. We need to integrate the social and the biological - to seek to better understand persons-organisms as "biosocial becomings".

Q: So developing a new conceptual vocabulary would seem to be very important. The notion of attending to "biosocial becomings" is intriguing - the emphasis on movement and becoming is clear, but are you advocating some form of sociobiology?

Absolutely not! One has to be careful with how one uses the term "biological". We should reject neo-Darwinian forms of naturalist epistemology that attempt to interpret the evolution of culture by establishing an analogy between genes and memes. This kind of reductionistic view of evolution is extremely dangerous. Evolution does not lie in the mutation, recombination, replication and selection of transmissible traits. It is rather a life process. And at the heart of this process is ontogenesis.

My aim is to restore the person to the continuum of organic life - not in the reductionist fashion of sociobiology, by putting it all down to genes, but by repositioning the organism as a locus of growth within a continuous field, and by thinking of evolution not statistically but topologically, as the unfolding of that field. Life is not in organisms; rather organisms are in life. Or in other words, living things are both generated and held in place within the ever-unfolding matrix of relations to which they contribute in their activity. This means giving a central place to growth and development in the constitution of life-forms.

\section{Q: Is this why you are so adamant in your dismissal of hylomorphism?}

Yes. In my 2013 work, Making, I attack the hylomorphism that is at the heart of the Neo-Darwinian view - the notion that the form of an organism is something already determined before its actual development. The fallacy of this way of thinking lies in supposing that the form miraculously precedes the processes that give rise to it. And the way to overcome the fallacy is simply to reverse the order, so as to give primacy to the process of ontogenesis - to the fluxes and flows of material entailed in making and growing - over the forms that arise within them.

For me, there are no objects. I see a world in the making, not a world already made. Making things is not an imposition of form on matter, as though the end were already settled before the task began. For how can form precede the processes that give rise to it? How can a known and determined future precede the present and the past? In my childish eyes, not knowing what the future holds, making is a never-ending task of worldweaving, a correspondence of material movement and ambient vision.

Q: Ontogenesis as a lively process of making and growing, which involves flows of material ... How does all this relate to conventional ecological conceptions of the relationship between organisms and their environment?

We are all, and have always been, organism-persons. But these organism-persons should not be thought of as bounded entities but as sites of binding, formed of knotted trails whose loose ends spread in all directions, tangling with other trails in other knots to form an ever-extending meshwork. As I have already described, this description of the organism-person would serve just as well for the fungal mycelium. 
And for this reason I have come to question what we mean by "the environment", and eventually to see it not as what surrounds - what is "out there" rather than "in here" - but as a zone of interpenetration in which our own and others' lives are comprehensively entangled. Within this zone, organisms grow to take on the forms they do, incorporating into themselves the lifelines of other organisms as they do so. Every organism is a site of infestation, a vast ecosystem in itself.

\section{Q: This emphasis on entanglement and growth suggests a very active role for organism- persons in producing their "environments"?}

Yes. This puts paid, once and for all, to the idea, still earnestly promulgated by many biologists and psychologists, that the child is a product of "nature" and "nurture", or of the interaction of genes and environment, in varying and often contested proportions. For children are not products, period. They are the producers of their lives with others, including grown-ups.

All knowledge is founded in skill, in the improvisatory exploration of ways of doing things, under the watchful eye of more experienced hands. This is how children learn: not through having knowledge first socially transmitted to them, and then enacting in practice what they each have individually acquired, but by growing in knowledge, as they do in strength and stature, by following the same paths as their predecessors and under their direction. It is a process, if you will, of guided rediscovery, in which every generation stands to find out for itself much of what its forbears already knew, and possibly much else besides. Learning, as children know very well but as their teachers so often do not, is a creative process in which knowledge is not so much passed on as perpetually grown and regrown. And if people differ in what or how they know, it is not because they have inherited different "packages" of transmitted representations, but because their lives have been entangled in environments, and in communities of practice, that differ in what they afford, in the kinds of attention they demand, and the responses that these demands call forth. Skill, in essence, inheres in the coordination of perception and action, attention and response. What we are used to calling cultural variation, then, consists in the first place in variations of skill. And to account for this variation we have to attend not to the content of inherited tradition but to the dynamics of ontogenetic development.

\section{Q: So the emphasis is on the porousness of boundaries between the human and non- human, organism and environment, and on their mutual interpenetration?}

Yes - the domain of the social and the biological are one and the same. The person is not so much a creature of society as an active and ongoing creator of his or her own and others' selves. In the new language of relationality, person-selves are seen as mutually constitutive.

Therefore, we must think of human beings in terms not of what they are but what they do. If we imagine life as a "line of becoming" it appears that cultural forms arise within the weave of life, in conjoint activity. That being the case, we must think of evolution not as change along lines of descent but as the developmental unfolding of the entire matrix of relations within which forms of life (human and non-human) emerge and are held in place. And it requires us to think of these forms as neither genetically nor culturally configured but as emergent outcomes of the dynamic self-organization of developmental systems.

\section{Q: If we problematize the common distinction between the "natural" and the "artificial", what are the implications for how we should conceive of activities like designing and building?}

I don't think, in the end, that we can sustain this division between the natural and the artificial, and it is probably not helpful to do so. But that also means, perhaps, substituting the word growing for building, because building always has this thing that you're putting something in place, whereas, growing gives the sense of a process going on under certain conditions. So, when a gardener says: "I'm growing these plants in my garden", it means that he is planting the seeds, putting in place certain conditions to favour the growth of those particular plants. But, still, other things are involved for the plant to grow. The gardener is not building it, in that sense.

The same argument you could make about the growth of a forest, you could also make about the growth of those kinds of structures that we tend to call artificial, like houses, or roads and the like. Can we think of these things as also grown, in the sense that the structure emerges out of a set of practices or processes? Some 
of these practices and processes might be undertaken by humans, and maybe in building a house, most of them are. But, still, other things always come in, houses have other animal inhabitants; then there is the weather, of course, and the sun, the rain and all sorts of other things with which you have to contend. So, the idea that a house is first built and then people come to live in it is, to some extent, part of an architectural conceit. It doesn't really match what actually happens.

So, rather than asking: "Do we have a division between natural and artificial?", I prefer to say that we are looking at processes by which the structures that we find in the world have grown. And, what are the conditions for growth? What has been the role of local communities in creating these conditions? And then we can ask: "What has been the role of the birds, what has been the role of the weather and everything else that has combined to create something?"

\section{Q: Let us shift now to a terrain that might be more familiar to an IS/OS readership. In your work, you have famously criticized Bruno Latour and actor-network theory. But, for us, you seem to have so much in common?}

There are many parallels between the conclusions that I arrive at and the conclusions that Latour arrives at. We are both destabilizing the dichotomy between Society and Nature, we are both thinking in terms of whether a network is the same as a meshwork or different. It depends on which page of Latour you happen to be reading, because he moves backwards and forwards. There are many points and areas where there is similarity, but we come from different places and that accounts for some of the differences.

I have several objections to Latour, but I particularly object to his blanket use of the non-human $-\mathrm{a}$ theory that attributes the same ontological weight to a speed bump or a gun or a key as is given to a living creature gives us a seriously reductionist view of what life is. I don't see how you can invoke a principle of symmetry. For instance, in the case of a grain of sand and a mite, they might weigh the same, but we are dealing with something fundamentally different, and that difference then is bound up for me with a focus on developmental processes that I think is crucial. Developmental processes, processes of growth, maturation, decay and decomposition, are fundamental to what I understand by life. I think that simply talking about anything as an actant loses that sense of what life is and I don't find a sense of what life is in Latour, not what I understand it to be, anyway.

Of course, Latour is taken in all sorts of different directions and many of them are directions that he himself would want to disown. Thus Latour's point is often taken to be that non-humans can have agency. But it's not as simple as that. In fact it is quite difficult to criticize Latour because, whichever way you cut it, you end up with a particular caricature of what he says. And this is because he is always changing what he says, or else saying what he said before while meaning something else. I shouldn't object to that because I change what I say, too. But I do find that at one moment he is saying that actor-network isn't a theory and is not actually about networks and at the next moment he's saying that actually it is a theory and it is about networks. This inconsistency creates some difficulties for me.

I would define life as the name for what is going on in the field of relationships within which organic forms emerge, develop and are held in place - that is what I understand as a life process. And I don't find that in Latour's understanding of the actor-network. I think, if you reduce life to agency and things to objects you effect a double reduction.

\section{Q: You mentioned earlier the importance of the idea of lines in your work. What are these lines? Or, what is it that the image of lines wants to convey?}

For me lines are about life, in the sense of lifelines. Lines imply movement and growth. Ways of moving, knowing and describing. They are lines of force, of growth and of movement, not outlines. Outlines enclose. Minds and lives are not closed-in entities that can be enumerated and added up; they are open-ended processes whose most outstanding characteristic is that they carry on.

\section{Q: But are lines then these lone travellers that just carry on ...?}

No, in carrying on, they wrap around one another, like the many strands of a rope. A whole that is made up from individual parts is a totality in which everything is articulated or "joined up". But the rope is always weaving, 
always in process and - like social life itself - never finished. Its parts are not elementary components but everextending lines, and its harmonies reside in the way each strand, as it issues forth, coils around the others and is coiled in its turn, in a countervalence of equal and opposite twists which hold it together and prevent it from unravelling. This interweaving of lines I call a meshwork - the trails along which life is lived. It is in the entanglement of lines, not in the connecting of points, that the mesh is constituted. A meshwork, in which every node is a knot. Indeed, I would suggest that in a world where things are continually coming into being through processes of growth and movement - that is, in a world of life - knotting is the fundamental principle of coherence.

\section{Q: That is interesting. What do you want to convey with this idea of a knot or knotting?}

Well, I will first say what knotting is not. The knot is not a building block. Blocks are assembled into structures; knots are bound or tied into nodes or nodules. Thus the order of the block is explicate, in that each is joined to the other by external contact or adjacency; the order of the knot is implicate, in that the constitutive strands of each knot, as they extend beyond it, are bound into others. Further, the knot is not a chain. Chains are articulated from rigid elements or links, and retain their connections even when tension is released. Yet they have no memory of their formation. Knots, by contrast, are not articulated and do not connect. They have no links. Nevertheless they retain within their constitution a memory of the process of their formation. The knot is not a container. Containers have insides and outsides; in the topology of the knot, however, it is impossible to say what is inside or outside. Rather, knots have interstices. Their surfaces do not enclose but lie "between the lines" of the materials that make them up.

\section{Q: So knotting is a way of joining, of being with, but that is very different from connecting ...?}

Yes, lines of life do not connect. They do not go from A to B, or vice versa. Rather, they pass between points without connecting, as the waters of a flowing river pass between its banks. It is the same in music or in painting. Whether it be the issue of the melody from the meeting of violin and bow or the motion of the brush and its trace, in the movement of becoming, points are not joined so much as swept aside and rendered indiscernible by the current as it sweeps through. Life is open-ended: its impulse is not to reach a terminus but to keep on going. In the meshwork, each constituent line, as it bodies forth, lays its own trail from within the interstices of its binding with others. Thus the joining of lives is also their continual differentiation. The knots formed in the process are not inclusive or encompassing, not wrapped up in themselves, but always in the midst of things, while their ends are on the loose, rooting for other lines to join with.

\section{Q: In one of your papers you make the distinction between joining "up" and joining "with", is this what you have in mind here?}

Yes. The adverb "up" connotes a finality that is belied by the ongoing life of the thing. It is no more joined up than used up. On the contrary, it carries on. In the meshwork, lines are joined not "up" but "with". Like the voices of choral music, whose harmony lies in their alternating tension and resolution, the entwined lines of the meshwork join with one another, and in so doing, possess an inner feel for each other and are not simply linked by external contiguity. I use the term sympathy to refer to this feel.

\section{Q: Is this notion of sympathy where your idea of correspondence comes in?}

For me correspondence is the co-responsive movement of occurrent things along their manifold lines of becoming. Maxine Sheets-Johnstone argues we must recognize that the key to both self-knowledge and organic life is movement. It is not just that bodies, as living organisms, move. They are their movements. Therefore, the knowledge they can have of themselves is inseparable from the sense they have of their own movements, or in a word, from kinesthesia. Animate beings, Sheets-Johnstone insists, do not experience themselves and one another as "packaged" but as moving and moved, in ongoing response - that is in correspondence - with the things around them.

In his reflections on upbringing in The Troubadour of Knowledge, Michel Serres compares this experience of being in-between - of correspondence - to that of the swimmer, breasting the current of a swift 
river. Here in the midstream, you enter a world unknown to those left standing on the banks. It is one in which, after a while, there is no longer any right bank or left bank, where you cease to be between this and that, where you have become a hyphen, a denizen of the in-between. Immersed in a fluid medium, always at risk of going under, you have no option but to keep on going, in a direction orthogonal to that of the line connecting the banks on either side. "The real passage", as Serres declares, "occurs in the middle". This goes to the heart of the distinction I want to draw between correspondence and interaction. Interaction goes back and forth as agents, facing each other on opposite banks of the river, trade messages, missiles and merchandise. But to correspond, in my terms, is to join with the swimmer in the midstream. It is a matter not of taking sides but of going along. Thus where interaction is transverse, correspondence is longitudinal.

Correspondence is not a connection of points but a binding of lines. It is not interactive but multilinear. And these lines, as we have seen, join not at the ends but in the middle. Ends are not given in advance but emerge in the action itself, and are recognizable as such only in acknowledging the possibility of new beginnings. Here, beginnings produce endings, and are produced by them. Every end is not a terminal but a moment along the way. Thus for the interaction of subjects, or intersubjectivity, I substitute the correspondences of the middle voice, and for the network of connected points, the meshwork of knotted and entangled lines.

\section{Q: We have explored a number of ideas. Maybe we can conclude. Given our conversation, what would you say to Information Systems and Organization Studies researchers, in terms of how they approach what they do?}

I would say that the world that they study is alive and open. In a world that is truly open there are no objects as such. For the object, having closed in on itself, has turned its back on the world, cutting itself off from the paths along which it came into being, and presenting only its congealed, outer surfaces for inspection. The open world, however, has no insides or outsides, only comings and goings. Such productive movements may generate formations, swellings, growths, protuberances and occurrences, but not objects. Our natural tendency, our habit of thought, leads us to suppose that the world is inhabited by entities that are already closed in upon themselves. It prevents us from seeing that life can be anything other than an interior property of things. Conceived as the creative potential of a world-in-formation, however, life is not in things; rather, things are in life, caught up in a current of continual generation. This is not a matter of putting life into things but of restoring those things to the movements that gave rise to them. It is not that they have agency, as is sometimes claimed; they are agency. The wind is its blowing, not a thing that blows.

Our "as if" world of science, the world of objects and relations, is explicate. The order of the social world, by contrast, is implicate. That is to say, any particular phenomenon on which we may choose to focus our attention enfolds within its constitution the totality of relations of which, in their unfolding, it is the momentary outcome. Were we to cut these relations, and seek to recover the whole from its now isolated fragments, something would be lost that could never be recovered. That something is life itself.

\section{Sources}

This interview has grown through the interpenetration of a range of different sources. Most notably, these include the following:

Ingold, T.: Up, Across and Along. Place and Location: Studies in Environmental Aesthetics and Semiotics. 5, $21-36(2006)$

Ingold, T.: Earth, Sky, Wind, and Weather. Journal of the Royal Anthropological Institute. 13, S19-S38 (2007)

Ingold, T.: Being Alive: Essays on Movement, Knowledge and Description. Routledge, London (2011)

Ingold, T.: Towards an Ecology of Materials. Annual Review of Anthropology. 41, 427-442 (2012) 
Ingold, T.: The Life of Lines. Routledge, Abingdon and New York (2015)

Ingold, T.: From Science to Art and Back Again: The Pendulum of an Anthropologist. ANUAC. 5(1), 5-23 (2016)

Ingold, T.: On Human Correspondence. Journal of the Royal Anthropological Institute (forthcoming, 2016)

Ingold, T., de Fiori, A.L., Alves Dias de Andrade, J.A., Queiróz Testa, A., Bassichetto Tambucci, Y.: Wayfaring Thoughts: Life, Movement and Anthropology - An Interview with Professor Tim Ingold. Ponto Urbe. 11 (2012). Available at: https://pontourbe.revues.org/341 (last accessed 10 October 2016)

Pitrou, P.: An Anthropology Beyond Nature and Culture? Tim Ingold and Gisli Palsson's Edited Volume, Biosocial Becomings. Somatosphere. 5 August (2015). Available at:

http://somatosphere.net/2015/08/an-anthropology-beyond-nature-and-culture-tim-ingold-and-gisli-palssonsedited-volume-biosocial-becomings.html (last accessed 10 October 2016) 